\title{
Current understanding of the aeronomy of Mars
}

\author{
Andrew F Nagy ${ }^{1}$ and Joseph M Grebowsky ${ }^{2 *}$
}

\begin{abstract}
This paper provides a short overview of our current understanding of the upper atmosphere/ionosphere of Mars including the escaping neutral atmosphere to space that plays a key role in the current state of the Mars upper atmosphere. The proper definition of the word "aeronomy" relates to the upper atmosphere where ionization is important. Currently there is a paucity of measurements of the internal physical structure of the Martian upper atmosphere/ionosphere. Much that we know has been deduced from theoretical models that predict many more things than thus far measured. The newest Mars orbital missions, the US MAVEN and Indian MOM missions, just beginning their science analyses, will provide the measurements needed to fully characterize the aeronomy of Mars.
\end{abstract}

Keywords: Mars; Aeronomy; Atmosphere; lonosphere; Escape

\section{Introduction}

The term aeronomy has been used since the 1950's, but its origin has been largely forgotten. Sydney Chapman first suggested, in a letter to Nature [1], that the word aeronomy should replace meteorology, given that the association of meteors is misleading. This suggestion was not followed so a number of years later [2] he modified his original idea and suggested that aeronomy instead of "being used to signify the study of the atmosphere in general, should be adopted with the restricted sense of the science of the upper atmosphere". This use of the term was accepted and has been in use ever since. In 1960 Chapman restated this definition [3] in a slightly different form by suggesting that aeronomy is the science of the upper region of the atmosphere where dissociation and ionization are important.

Our current understanding of the aeronomy of Mars is very limited. The two Viking landers each carried a mass spectrometer [4] and a retarding potential analyzer [5]. Thus we have insitu neutral gas composition and plasma density, composition and temperature information from only the equivalent to a single sounding rocket flight. The other in-situ plasma composition data, comes from the ASPERA instrument [6] on Mars Express (MEX), which has been providing information on the density, composition and energy of ions and electrons of energies between about $10 \mathrm{eV}$ to $\sim 36 \mathrm{keV}$ at altitudes

\footnotetext{
* Correspondence: Joseph.m.grebowsky@nasa.gov

${ }^{2}$ GSFC/NASA, Greenbelt, MD, 20771, USA

Full list of author information is available at the end of the article
}

beyond about $300 \mathrm{~km}$. Much electron density data exists from the MARSIS instrument on MEX [7] from in situ and remote wave sounding - spottily from radio occultation observations obtained on early missions (e. g. Mariners, Viking, Russian "Mars" missions) and more comprehensively from the radio science limb occultation experiments on the more recent Mars Express [8] and Mars Global Surveyor [9] missions. The same Mars missions also provided some remote and inferred atmosphere information from UV occultation, from low altitude aerobreaking-phase satellite drag data (MRO, MGS, Odyssey) and more extensively from Mars Global Surveyor (MGS), reflectometer measurements of atmospherescattered electron pitch angle distributions (e.g.,[10]). Finally the analogy between Mars and Venus, with similar atmosphere composition and regions with no intrinsic surface magnetic fields, has also provided important insights about the aeronomy of this poorly studied region of Mars. This is a lot of information, particularly of the electron density distributions. However, we have only glimpses of the overall complexity of the atmosphere and plasma states - there is, as of now, almost a complete absence of the thermal, composition and dynamical parameters that define the underlying physics of the Martian aeronomy.

\section{Review}

\section{Neutral upper atmosphere}

The Viking 1 and 2 mass spectrometers on entry obtained mass spectra from 1 to $49 \mathrm{amu}$ [4]. They sampled the atmosphere under not very different solar illumination locations and solar activity. The composition data from Viking 
1 is shown in Figure 1. Atomic oxygen, a very important neutral gas species for understanding the aeronomy, was not measured by these instruments. The density of $\mathrm{O}$, which has been widely used, was deduced from the presumed chemistry of the measured ion composition. Figure 2 shows results from a theoretical model, indicating that many other minor species are expected to be present. The temperatures derived from the Viking data [11] are shown in Figure 3, which implies the presence of significant wave activity.

Given this very limited direct observation of the atmospheric altitude variation, plus globally patchy statistical measurements of the density from accelerometer measurements, comprehensive 3D thermospheric circulation models (e.g.,[13,14]), constrained by the measurements, have been developed during the last decade. Such models solve the coupled continuity, momentum and energy equations and provide the densities, temperature and velocities of the major species. These models have been very helpful to achieve a global understanding of the behavior of the upper atmosphere. Figure 4 shows results from such a model which are consistent with measured parameters, but the model predicts spatial changes in the distributions and provide clues for parameters, such as neutral velocities for which no direct data is available.

\section{lonosphere}

As indicated in the introduction, each of the two Viking landers carried a retarding potential analyzer, which provided information on the major ion densities and plasma temperatures in the ionosphere up to an altitude of about $300 \mathrm{~km}$ as shown in Figures 5 and 6 . Note that two spacecraft vertical profiles are very similar

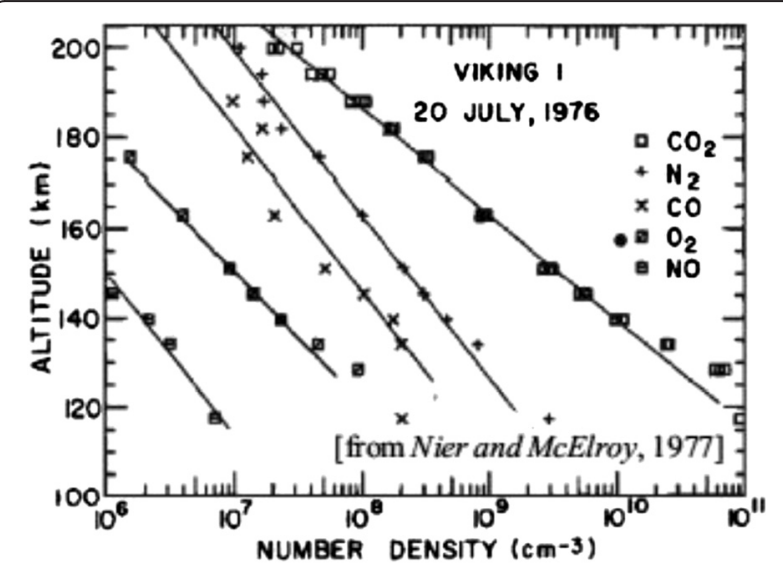

Figure 1 Viking neutral measurements. Observations of neutral composition from one of the two Viking lander entry probes, both of which took place on the dayside of Mars within one month of one another and at nearly the same solar zenith angles.
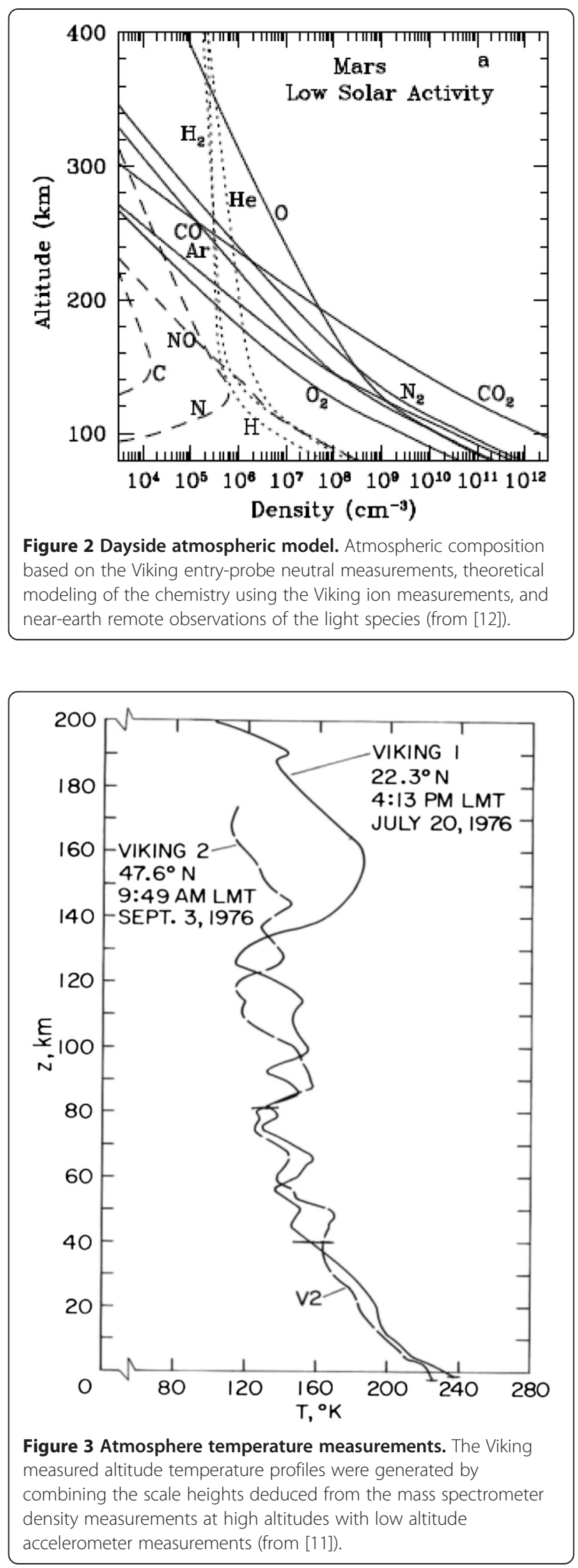


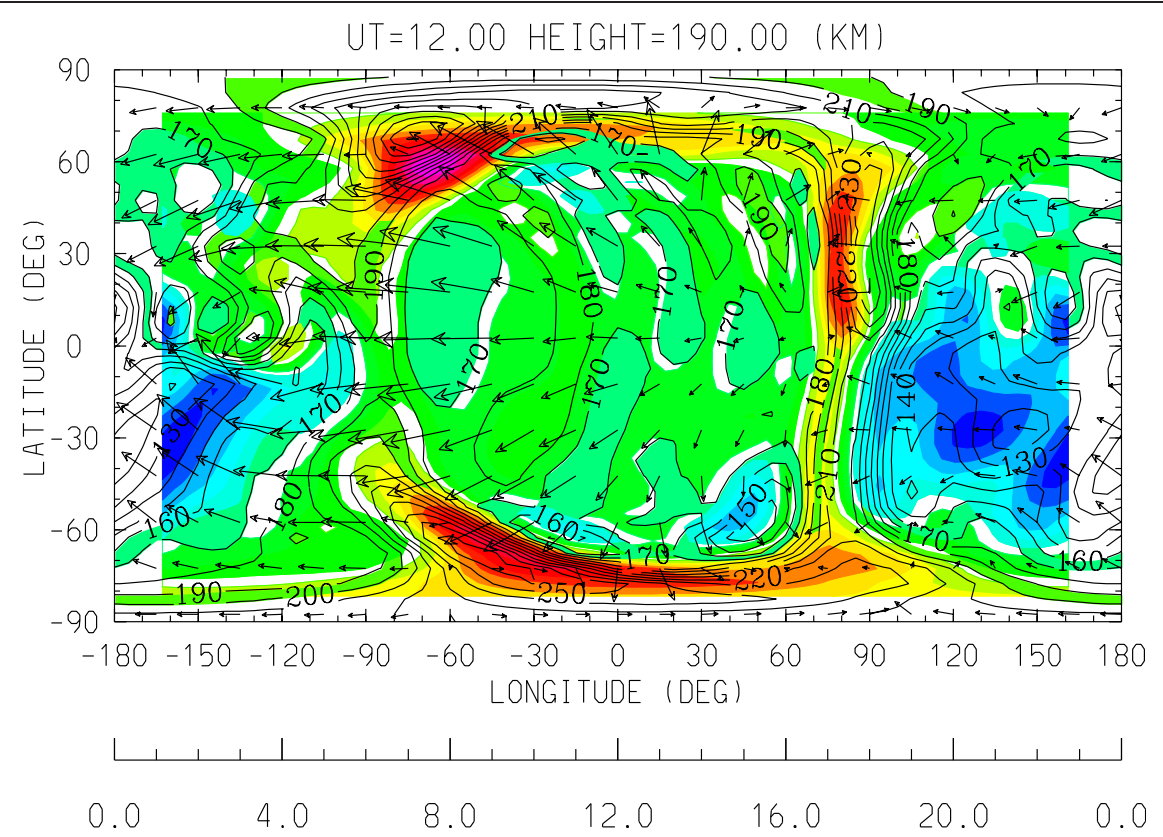

Figure 4 Neutral atmosphere model. Shown are calculated gas temperatures and velocities at $190 \mathrm{~km}$ for equinox solar cycle minimum conditions. (1) Minimum temperatures are in blue and correspond to 115-130K (nightside); (2) Moderate temperatures in green correspond to 170-180K (mostly dayside, low SZA); (3) Maximum temperatures in red correspond to 250-290K (high latitude and evening terminator). Temperature increments are $10 \mathrm{~K}$ throughout. Maximum area for horizontal wind is $\sim 350 \mathrm{~m} / \mathrm{s}$ [15].
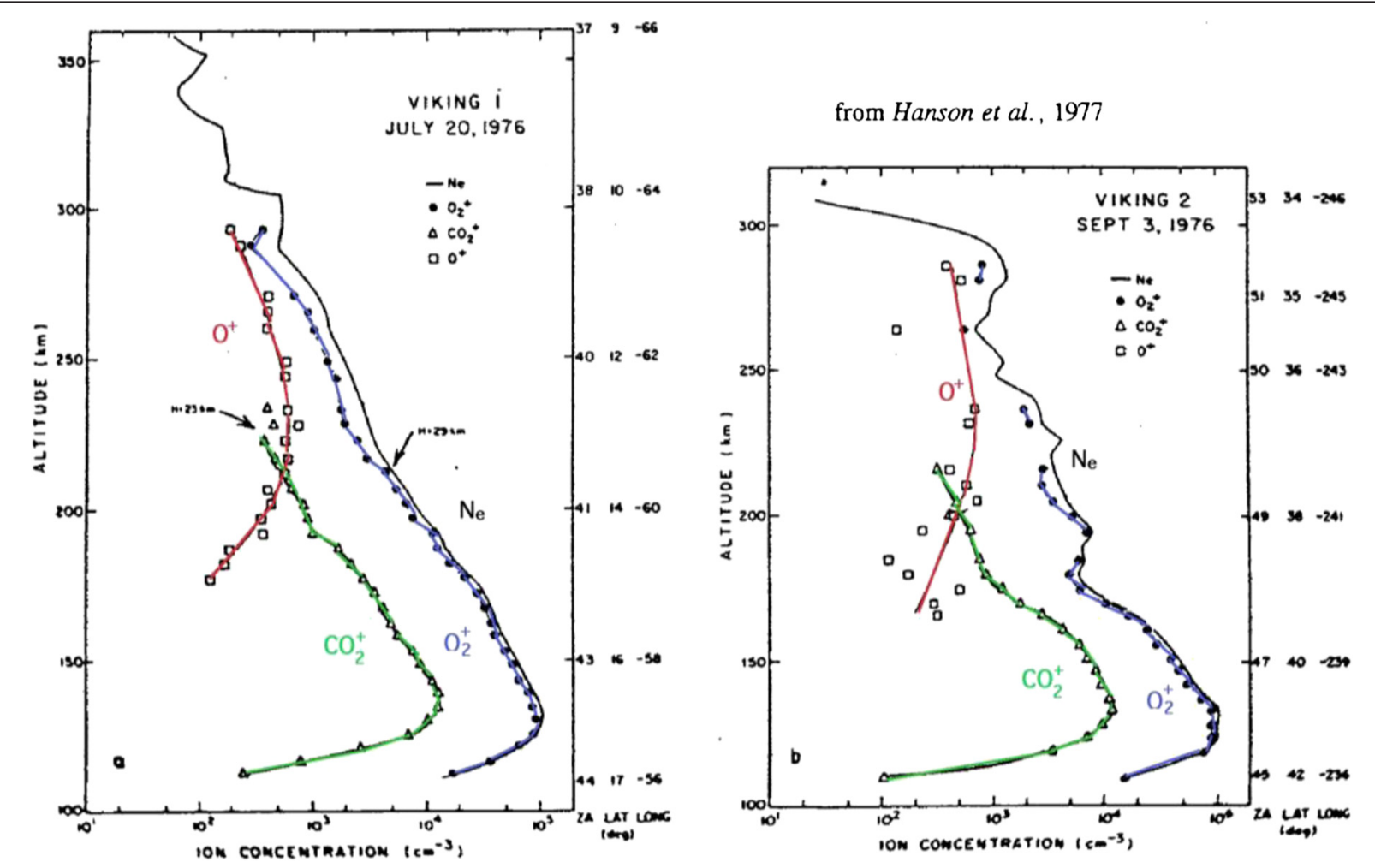

Figure $\mathbf{5}$ Viking ion measurements. The only Mars ion composition measurements were from the two Viking entries in the dayside under quite similar solar conditions. One question is whether $\mathrm{O}^{+}$ever becomes dominant at high altitudes. Electron temperatures and ion velocities were also sampled - with the observation that there are large horizontal motions at high altitudes. (from [16]). 

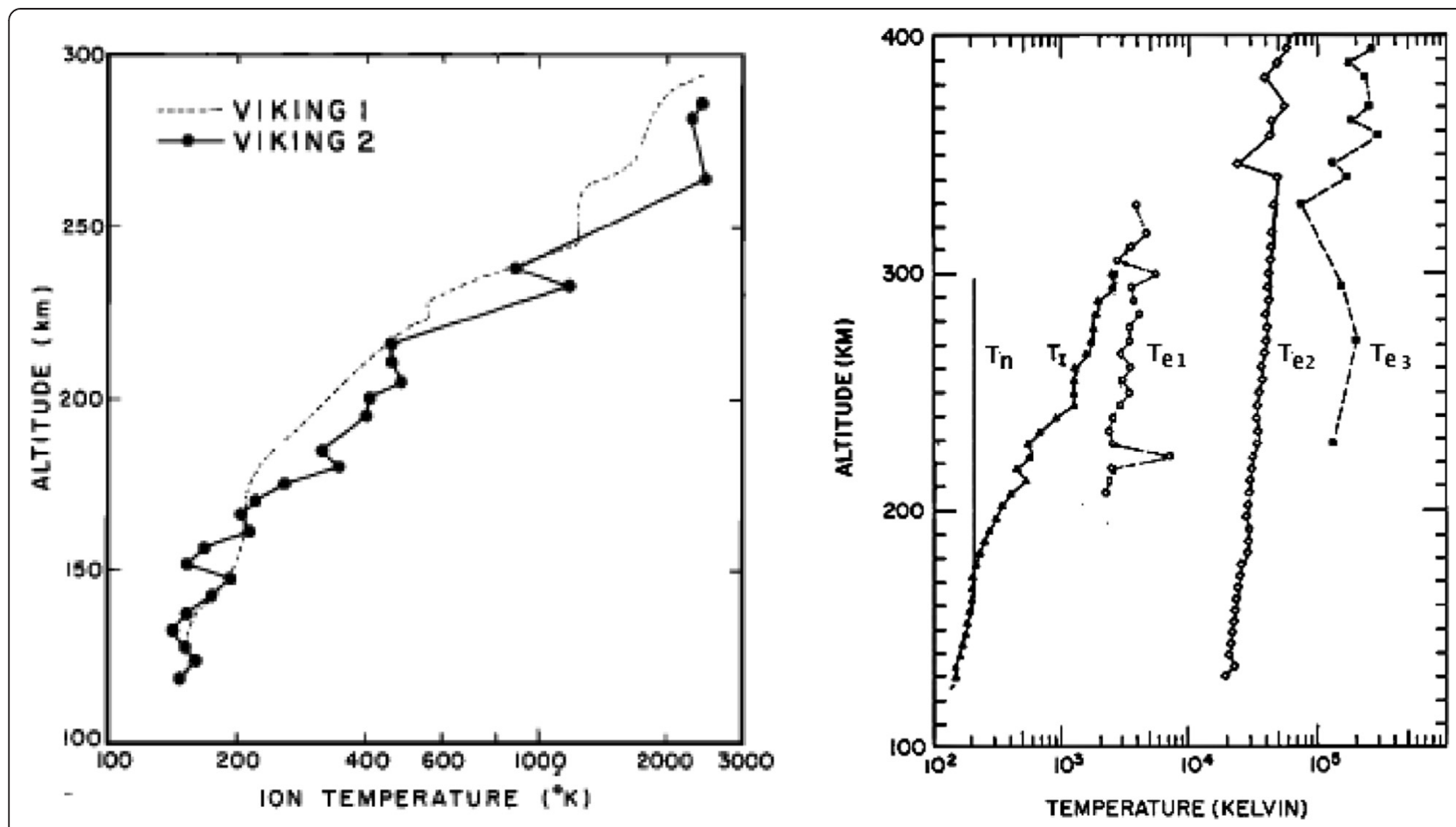

Figure 6 Viking plasma temperatures. Temperature profiles measured by the two Vikings $[5,16]$ were nearly identical. On the Viking 1 entry (right), the ion temperature increased from the low altitude neutral temperature $T_{n}$ (deduced from the neutral scale height) to the measured thermal electron temperature $T_{e 1}$ at high altitudes. The electron temperatures $T_{e 2}$ and $T_{e 3}$ are inferred estimates of the presence of photoelectrons and a hotter population from the magnetosheath. Tr and Tc are theoretical models of the electron temperature from [4] and [17].

and equivalent to data from a single sounding rocket flight and that is all the data available to date. In order to attempt to understand the implication of this extremely minimal data set, we need to use extensive model calculations and invoke the similarities between the ionospheres of Mars and Venus. Carbon dioxide is the major neutral constituent of both planets, with atomic oxygen becoming dominant above about 200 and $150 \mathrm{~km}$, respectively. The Viking RPA's measurements detected ion flows of $\sim 100 \mathrm{~m} / \mathrm{s}$ at high altitudes and the fact that Mars has remnant crustal magnetic fields introduces complexity in the transport processes above the chemical equilibrium region $(\leq 200 \mathrm{~km})$, but the basic parent sources of the two ionosphere regions are very similar. The controlling chemical processes are:
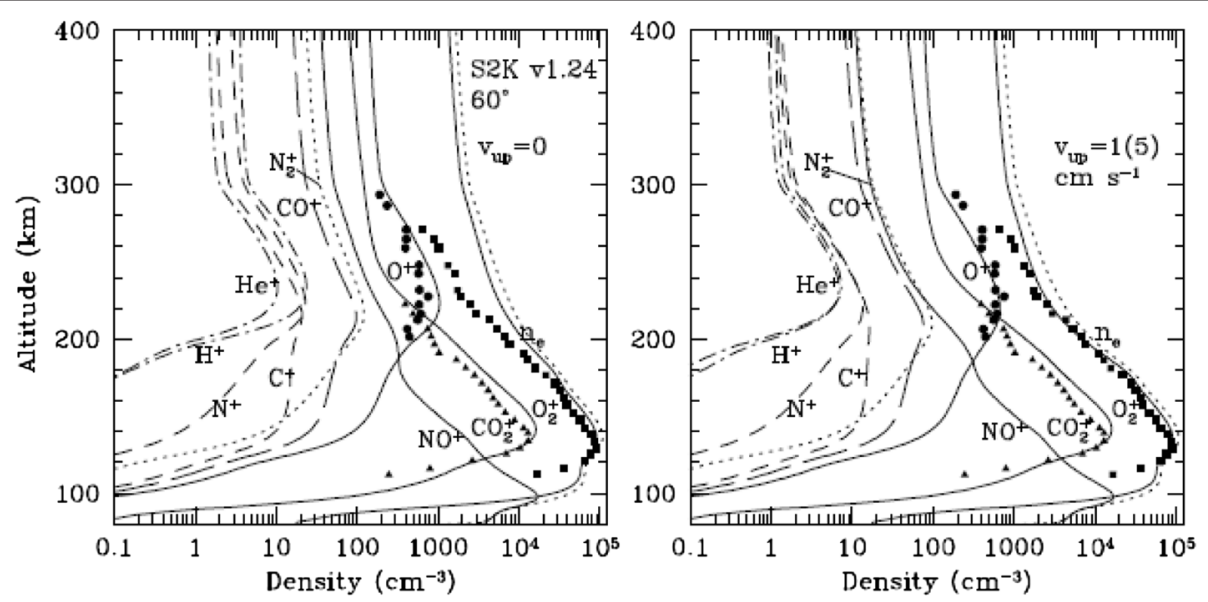

Figure 7 Modeled 1-D ion composition. [18] modeled 14 ions: $\mathrm{CO}_{2}^{+}, \mathrm{Ar}^{+}, \mathrm{N}_{2}^{+}, \mathrm{O}^{+}(4 \mathrm{~S}), \mathrm{O}^{+}(2 \mathrm{D}), \mathrm{O}^{+}(2 \mathrm{P}), \mathrm{CO}^{+}, \mathrm{C}^{+}, \mathrm{N}^{+}, \mathrm{O}_{2}^{+}, \mathrm{NO}^{+}, \mathrm{O}^{++}, \mathrm{H}^{+}, \mathrm{He}$. As seen the model matches the total ion/electron measurements of Viking 1 with an assumed upward ion flow (right frame), but many species are predicted in the models that have yet to be measured. 


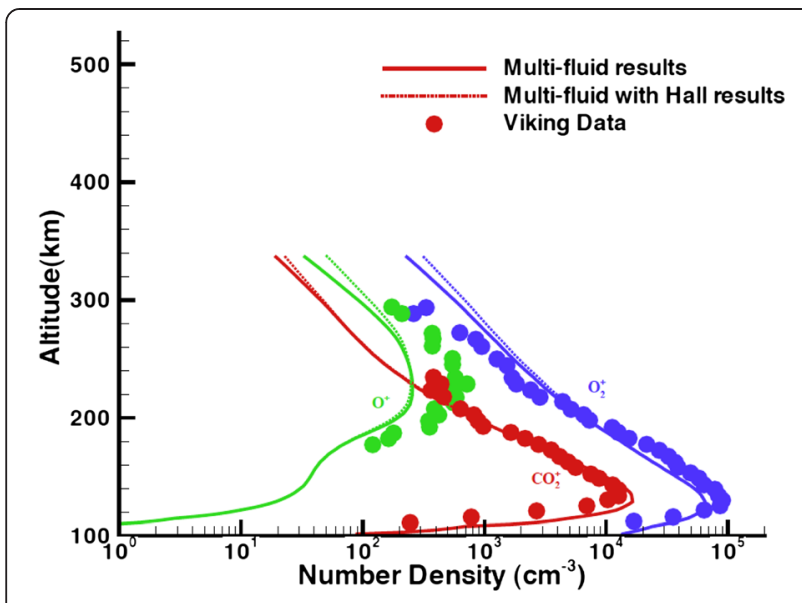

Figure 8 MHD 3-D ion model. Viking 1 ion density measurements are compared to model calculations of [19]. The lack of good agreement in $\mathrm{O}^{+}$is the result of the uncertainty in neutral $\mathrm{O}$ densities; excellent agreement could be achieved by adjusting the neutral $O$ density values, which were originally obtained by fitting a different model.

\section{- Dominant photoionization parent is $\mathrm{CO}_{2}$ :}

$$
\mathrm{CO}_{2}+\mathrm{h} v \rightarrow \mathrm{CO}_{2}^{+}+\mathrm{e}^{-}
$$

- (minor photo-ions are also produced: $\mathrm{O}^{+}, \mathrm{N}_{2}^{+}$, $\mathrm{CO}^{+}, \mathrm{O}_{2}^{+}, \mathrm{NO}^{+}, \mathrm{H}_{2}^{+}$)

- Ion-neutral chemical interactions transforms species: $\mathrm{O}_{2}^{+}$produced by:

$$
\begin{aligned}
& \mathrm{CO}_{2}^{+}+\mathrm{O} \rightarrow \mathrm{O}_{2}^{+}+\mathrm{CO} \\
& \text { and } \\
& \mathrm{O}^{+}+\mathrm{CO}_{2}^{--}>\mathrm{O}_{2}^{+}+\mathrm{CO}
\end{aligned}
$$

(the charge exchange reactions indicated above are very fast so $\mathrm{O}_{2}{ }^{+}$dominates the ionosphere composition)

\section{- Ion loss is via dissociative recombination:}

$$
\mathrm{O}_{2}^{+}+\mathrm{e}^{-} \rightarrow \mathrm{O}+\mathrm{O}
$$

This ion chemistry leads to the, initially unexpected result, that in an atmosphere that basically has no molecular oxygen, the major ion is $\mathrm{O}_{2}^{+}$. Figure 7 shows the results from a 1D chemical-diffusion model ([18]) that reproduces the Viking observations (assuming a certain topside ion outflow) and also shows that many important minor ion species are also expected to be present.

Such a 1D model is very important, because it can include the many important chemical processes; however it requires a number of important assumptions (e.g. upper boundary ion flow and plasma temperature). We also have 3D MHD models, which self-consistently solve the plasma continuity, momentum and energy equations from below the main ionosphere well out into the solar wind. However there is always a price to pay; such a model given limited computational resources can only consider the main ions $\left(\mathrm{O}_{2}^{+}, \mathrm{O}^{+}, \mathrm{CO}_{2}^{+}\right)$. The results from such a model [19] are shown in Figure 8.

It was established decades ago, using the large Pioneer Venus data base, that the observed ionosphere temperatures at Venus, required either i) a reasonable, but ad hoc energy inflow at the top of the ionosphere and/or ii) a reduced electron thermal conductivity. The plasma temperatures measured by the RPA's on Viking shown in Figure 6 also increase enough with increasing altitude to require the ad hoc energy input assumptions, as needed in the case of Venus. Figure 8 shows the results of a model ion composition calculation that used a reasonable topside heat inflow to match the observed ion temperatures from Viking and that agrees with the Viking composition measurements. Currently it is clear that conventional EUV heating and classical thermal conductivity lead to temperature values below the observed ones both

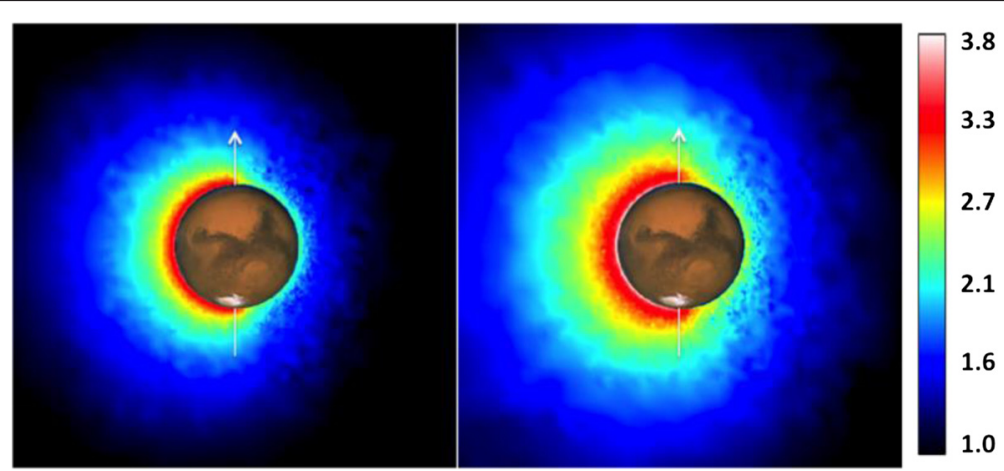

Figure 9 Oxygen corona. Calculated hot oxygen densities in the meridional plane for low and high solar activity from [24] (the color scale denotes log density in $\mathrm{cm}^{-3}$ ). 
at Mars and Venus and there is insufficient information to establish if either or both of the processes suggested to remedy this problem are in effect active. It is quite likely that both play a role, but whether one or the other dominate, or some other process is active, cannot be established at this time. Note that two review papers have been published recently that deal with details of the ionosphere of Mars [20,21].

\section{Exosphere and Atmospheric Escape}

At both Mars and Venus a hot oxygen corona has been observed to be present $([22,23])$. These fast energetic oxygen atoms are mostly created by dissociative recombination of molecular oxygen ions (some other processes, such as dissociative recombination of $\mathrm{CO}^{+}$also make a contribution).

$$
\begin{aligned}
\mathrm{O}_{2}^{+}+e & \rightarrow O\left({ }^{3} P\right)+6.99 e V \\
& \rightarrow O\left({ }^{3} P\right)+O\left({ }^{1} D\right)+5.02 e V \\
& \rightarrow O\left({ }^{3} P\right)+O\left({ }^{1} S\right)+2.80 e V \\
& \rightarrow O\left({ }^{1} D\right)+O\left({ }^{1} S\right)+0.84 e V \\
& \rightarrow O\left({ }^{1} D\right)+O\left({ }^{1} S\right)+0.84 e V
\end{aligned}
$$

Sophisticated 3D Monte Carlo models have been developed to quantify the distribution of these atoms around Mars [15]. An example of such predicted spatial distribution is shown in Figure 9.

The maximum energy of a hot oxygen created by the dissociative recombination of $\mathrm{O}_{2}^{+}$is about $3.5 \mathrm{eV}$; this energy is too low to allow it to escape from Venus, but is well above the necessary escape energy of Mars $(\sim 2 \mathrm{eV})$, thus resulting in a significant escape flux. Estimates of oxygen escape are indicated in Table 1 [25]; note the significant variation with orbital location and solar insolation.

The other process by which the atmosphere can be depleted is ion escape. Ion escape has been measured extensively by the ASPERA instrument on Mars Express $([26,27])$ and also widely modeled (e.g. [24,28-30]) and there is reasonably good agreement between the measured

\begin{tabular}{|c|c|c|c|c|}
\hline Escape rate $\left(10^{25} s^{1}\right)$ & $\begin{array}{l}\text { Vernal } \\
\text { equinox }\end{array}$ & $\begin{array}{l}\text { Autumnal } \\
\text { equinox }\end{array}$ & Aphelion & Perihelion \\
\hline Solar minimum & 1.30 & 1.61 & 1.14 & 1.74 \\
\hline Solar moderate & 2.03 & 2.5 & 1.82 & 3.29 \\
\hline Solar maximum & 2.87 & 3.83 & 2.71 & 5.18 \\
\hline
\end{tabular}
and calculated values. Figure 10 shows the measured solar cycle variation obtained from Mars Express and Table 2

Table 1 Calculated neutral atomic oxygen escape fluxes [21]

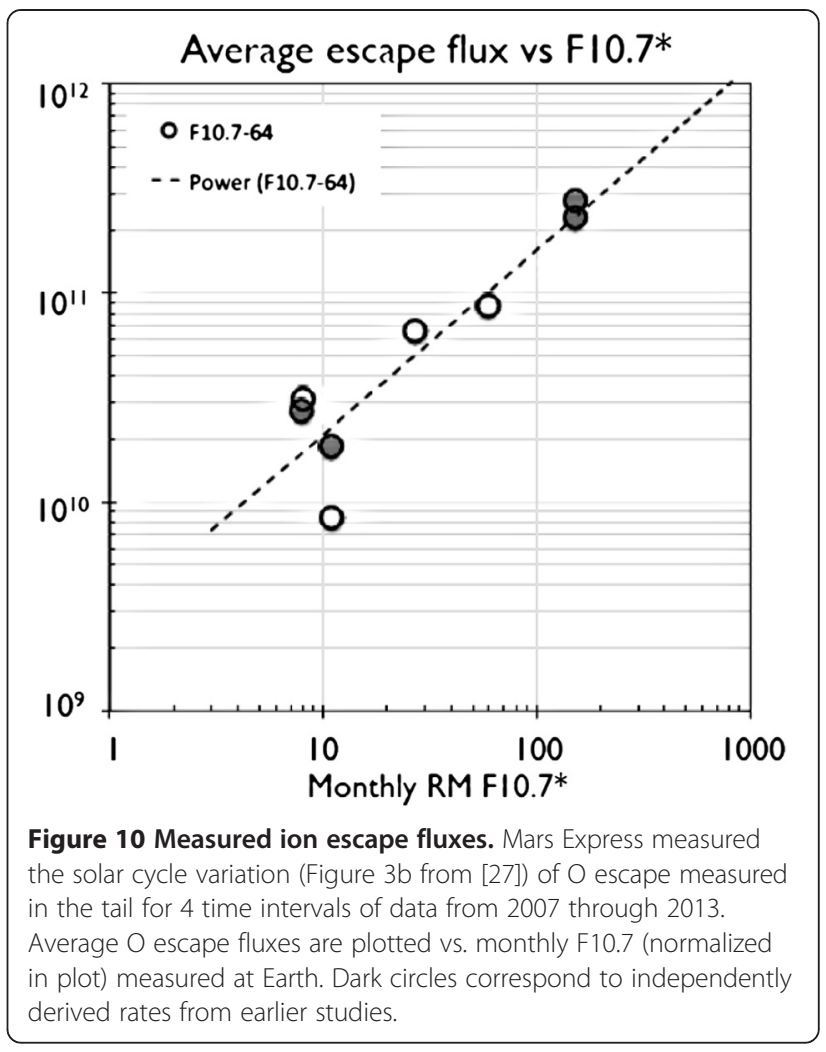

shows the results of the most recent calculations by Dong et al. [28].

\section{Conclusions}

As outlined in the introduction the amount of direct information available at this point on the aeronomy of Mars is extremely limited. However, that is changing very rapidly. There are two spacecraft, recently beginning science operations, in orbit around Mars (both were inserted into orbit late September 2014) carrying instruments that will provide a wealth of new information. The Indian Mars Orbiter Mission (MOM) carries three aeronomy related instruments: a methane sensor, a quadrupole neutral mass spectrometer and a Lyman alpha photometer. The US Mars Atmospheric Volatile Escape Mission (MAVEN) has 9 instruments on board all designed to address a wide range of aeronomy related

Table 2 Modeled ion escape fluxes $\left(\mathrm{s}^{-1}\right)$ of dominant ion species [10]

\begin{tabular}{llllll}
\hline NeutralProfile & $\begin{array}{l}\text { Simulation } \\
\text { Cases }\end{array}$ & $\mathbf{O}^{+}$ & $\mathbf{O}_{\mathbf{2}}^{+}$ & $\mathbf{C O}_{\mathbf{2}}^{+}$ & Total \\
\hline 3D MTGCM & Case 1 & $4.2 \times 10^{23}$ & $1.7 \times 10^{24}$ & $3.5 \times 10^{23}$ & $2.5 \times 10^{24}$ \\
& Case 2 & $3.7 \times 10^{24}$ & $2.5 \times 10^{24}$ & $3.8 \times 10^{23}$ & $6.6 \times 10^{24}$ \\
& Case 3 & $1.0 \times 10^{25}$ & $2.5 \times 10^{25}$ & $8.2 \times 10^{24}$ & $4.3 \times 10^{25}$ \\
\hline
\end{tabular}

Case 1 solar minimum conditions; case 2: solar maximum; and case 3: solar maximum with a disturbed solar wind. Fluxes in $\mathrm{s}^{-1}$. 
issues. After the completion of the Pioneer Venus Orbiter mission we could confidently state that we knew more about the aeronomy of Venus than any other planet in our solar system except for Earth. We are confident that in the next year or two we will be able to say the same about Mars.

\section{Competing interests}

The authors declare that they have no competing interests.

\section{Authors' contributions}

This paper was presented as a "Distinguished Lecture" at the 2014 AOGS Meeting held in Sapporo, Japan. AFN was the recipient of the "Distinguished Lecture" award, but because of unforeseen circumstances was unable to attend the meeting, so his lecture was presented by JMG. Both authors read and approved the final manuscript.

\section{Authors' information}

Professor Nagy has over forty five years of experience in both theoretical and experimental studies of the upper atmospheres, ionospheres and magnetosphere of the Earth and planets. He was principal and co-investigator of a variety of space-borne instruments. He was Interdisciplinary Scientist for the Dynamic Explorer and Pioneer Venus programs. He is a team member of the Radio Science Investigation on Cassini and a co-investigator of the MAVEN mission. He has been a principal or co-author of over 350 papers; he has also authored/co-authored a number of review papers and encyclopedia chapters and a book on the "ionospheres".

Dr. Grebowsky started his working career analyzing measurements of ion composition measurements from the Atmosphere Explorer and OGO satellites. Subsequently he was principal scientist on ion measurements from the Plasma Diagnostic Package flown twice on the Space Shuttle, and co-investigator for the ion spectrometers on the Midcourse Space Experiment and Pioneer Venus Orbiter., the Earth's thermosphere/ionosphere, ionospheremagnetosphere coupling. He is currently NASA's Project Scientist for the Mars MAVEN mission. His research efforts and publications dealt with Venus, Mars and terrestrial ionospheres and upper atmospheres, spacecraft plasma environments, meteoric ion and neutral species layers at Earth and other planets.

\section{Acknowledgements}

The authors acknowledge financial support for their Mars related activities from the NASA MAVEN project.

\section{Author details}

'University of Michigan, Ann Arbor, Ml 48109, USA. 'GSFC/NASA, Greenbelt, MD, 20771, USA.

Received: 22 September 2014 Accepted: 20 January 2015

Published online: 10 April 2015

\section{References}

1. Chapman S (1946) Some thoughts on nomenclature. Nature 157:405-405, doi:10.1038/157405b0

2. Chapman S (1953) Nomenclature in meteorology. Weather 7-8:62

3. Chapman S (1960) The thermosphere - the Earth's outermost atmosphere. In: Ratcliffe JA (ed) Physics of the Upper Atmosphere. Academic Press, New York, pp 1-2

4. Nier AO, McElroy MB (1977) Composition and structure of Mars's upper atmosphere: results from the neutral mass spectrometers on Viking 1 and 2. J Geophys Res 82:4341

5. Hanson WB, Sanatani DR, Zuccaro DR (1977) The Martian ionosphere as observed by the Viking retarding potential analyzers. I Geophys Res 82:4351

6. Barabash S, Federov LR, Sauvaud J-A (2007) Martian atmospheric erosion rates. Science 315:501-503. doi:10.1126/science.1134358

7. Gurnett DA, Kirchner DL, Huff RL, Morgan DD, Persoon AM, Duru F, Nielsen E, Safaeinilli A, Plaut JJ, Picardi G (2005) Radar Soundings of the lonosphere of Mars. Science 310:1929, Doi: 10.1126/science.112186

8. Pätzold M, Tellmann S, Häusler B, Hinson D, Schaa R, Tyler GL (2005) A sporadic third layer in the ionosphere of Mars. Science 310:837-838
9. Hinson DP, Simpson RA, Twicken GL, Flasar FM (1999) Initial results from radio occultation measurements with Mars Global Surveyor. J Geophys Res $104: 26,997-27,012$

10. Lillis RJ, Engel JH, Mitchell DL, Brain DA, Lin RP, Bougher SW, Acunã MH. (2005) Probing upper atmosphere neutral densities at Mars using electron reflectometry. Geophys Res Lttrs, 32: L23204. doi:10.1029/2005GL024337, 2

11. Sieff A, Kirk DB (1977) Structure of the atmosphere of Mars in summer at mid-latitudes. J Geophys Res 82:4364-4378

12. Fox JL, Hac A (2010) Isotope fractionation in the photochemical escape of O from Mars. Icarus 208:16. doi:10.1016/j.icarus.2010.01.19

13. Bougher SW, Blelly P-L, Combi MR, Fox JR, Meuller-Wodarg, Roble RG (2008) Neutral upper atmosphere and ionosphere modeling. Space Sci Rev 139. doi:10.1007/s11214-008-9383-7

14. Forget F, Hourdin F, Fournier R, Hourdin C, Talagrand O, Colins M, Lewis SR, Read PL, Hout J-P (1999) Improved general circulation models of the Martian atmosphere from the surface to above $80 \mathrm{~km}$. J Geophys Res 104:24155. doi:10.1029/1999JE001025

15. Valeille A, Combi MR, Bougher SW, Tenishev V, Nagy AF (2009) Threedimensional study of Mars upper thermosphere/ionosphere and hot oxygen corona: General description and results at equinox for solar low conditions. J Geophys Res Planets 114: E11005. doi:10.1029/2009JE003388

16. Hanson WB, Mantas GP (1988) Viking electron temperature measurements: evidence for a magnetic field in the Martian ionosphere. J Geophys Res 93:7538

17. Chen RH, Cravens TE, Nagy AF (1978) The Martian ionosphere in light of the Viking observations. J Geophys Res 83:3871

18. Fox $J$ (2009) Morphology of the dayside ionosphere of Mars: Implications for ion outflows. J Geophys Res 114:E12005. doi:10.1029/2009JE003432

19. Najib D, Nagy AF, Tóth G, Ma Y (2011) Three-dimensional, multifluid, high spatial resolution MHD model studies of the solar wind interaction with Mars. J Geophys Res 116:A05204. doi:10.1029/2010J016272

20. Haider SA, Mahajan KK, Kallio E (2011) Mars ionosphere: A review of experimental and modeling studies. Rev Geophys 49:RG4001. doi:10.1029/ 2011 RG00035

21. Haider SA, Mahajan KK (2014) Lower and upper ionosphere of Mars. Space Sci Rev 182:19. doi:10.1007/s11214-014-0058-2

22. Feldman PD, Steffi AJ, Parker JW, A'Hearn MF, Beratux JL, Stern AS, Slater DC, Versteeg M, Throop HB, Cunningham NJ, Feaga LM. (2011) Rosetta-Alice observations of exospheric hydrogen and oxygen on Mars. Icarus 214:394. doi:10.1016/j.icarus.2011.06.013

23. Nagy AF, Cravens TE, Yee J-H, Stewart AIF (1981) Hot oxygen atoms in the upper atmosphere of Venus. Geophys Res Lett 8:629

24. Ma YJ, Nagy AF (2007) lon escape fluxes from Mars. Geophys Res Lett 34:L08201. doi:10.1029/2006GL029208

25. Lee Y (2014) A 3-dimensional kinetic particle simulation of the Martian hot coronae and upper atmosphere: Mechanism, structure, variability and atmospheric loss. Ph. D. thesis, The University of Michigan, archived at http://deepblue.lib.umich.edu/handle/2027.42/110476

26. Barabash S, Lundin R, Andersson H, Brinkfeldt K, Grigoreiv A, Gunell H, Hollmström M, Yamauchi M, Asamura K, Bochhsler P, Wurz P, Cerulli-Irelli R, Mura A, Milillo A, Maggi M, Orsini S, Coates AJ, Linder DR, Kataria DO, Curtis CC, Hsieh KC, Sandel BR, Frahm RA, Sharber JR, Winningham JD, Grande M, Kallio E, Koskinen H, Rllhelä P, Schmidt W, et al. (2006) The analyzer of space plasmas and energetic atoms (ASPERA-3) for the Mars Express mission. Space Sci Rev 126:113-164

27. Lundin R, Barabash S, Holmström M, Nilsson H, Futaana Y, Ramstad R, Yamauchi M, Dubinin E, Fraenz M (2013) Solar cycle effects on the ion escape from Mars. Geophys Res Lett 40:6028. doi:10.1002/2013GL058154

28. Dong C, Bougher SW, Ma Y, Toth G, Nagy AF, Najib D (2014) Solar wind interaction with Mars upper atmosphere: Results from one-way coupling between the multifluid MHD model and the MTGCM model. 41:2708. doi:10.1002/2014GL059515: 2708-2715.

29. Brecht SH, Ledvina SA (2014) The role of the Martian crustal magnetic fields in controlling ionospheric loss. Geophys Res Lett 41:5430. doi:10.1002/ 2014GL060841

30. Valeille A, Combi MR, Tenishev V, Bougher SW, Nagy AF (2010) A study of suprathermal oxygen atoms in Mars upper thermosphere and exosphere over the range of limiting conditions. Icarus 206:18. doi:10:1016/j. icarus.2008.08.018 